\title{
A INSTRUMENTALIDADE NO TRABALHO DA ASSISTENTE SOCIAL NOS SERVIÇOS DE SAÚDE DE MÉDIA COMPLEXIDADE EM TIMON (MA) ${ }^{1}$
}

\author{
Violêta Maria da Silva Nolêto ${ }^{2}$ \\ Universidade Federal do Piauí (UFPI)
}

\section{RESUMO}

O trabalho do assistente social exige do profissional o conhecimento e uso da instrumentalidade em sua intervenção no campo da saúde. $O$ presente artigo tem por objetivo compreender a instrumentalidade no trabalho da assistente social nos serviços de saúde de Média Complexidade no município de Timon-MA. O estudo é um recorte da pesquisa de Mestrado do Programa de Pós-Graduação em Políticas Públicas da Universidade Federal do Piauí-UFPI. A metodologia adotada foi a pesquisa qualitativa, com análise de literatura, pesquisa documental e pesquisa de campo, que envolveu cinco instituições de saúde de Média Complexidade do município de Timon, tendo contado com a participação de cinco assistentes sociais que intervém nesse nível de complexidade no SUS. A pesquisa de campo foi realizada por meio de respostas aos questionários e as narrativas nos grupos focais. No contexto investigado, as assistentes sociais, revelaram que a potência do seu trabalho na saúde e o uso da instrumentalidade está marcada pelo diálogo e pela escuta do usuário, pelo acolhimento visando a humanização do atendimento e a busca da fruição do acesso mediadas por densos processos de encaminhamentos à Rede de Atenção à Saúde e para a Rede Socioassistencial, assinalam com ênfase o seu trabalho diário na defesa da vida e da cidadania.

Palavras-Chave: Atenção Secundária. Sistema Único de Saúde. Trabalho. Serviço Social. Instrumentalidade

\section{ABSTRACT}

The work of the social worker demands from the professional the knowledge and use of instrumentality in his or her intervention in the health field. This article aims to understand the instrumentality in the work of social workers in health services of Medium Complexity in the city of Timon-MA. The study is a clipping of the Master's research of the Postgraduate Program in Public Policies of Universidade Federal do Piauí-UFPI. The methodology adopted was the qualitative research, with literature analysis, documentary research and field research, which involved five Medium Complexity health institutions in the city of Timon-MA, with the participation of five social workers who intervene in this level of complexity in SUS. The field research was carried out by means of answers to the questionnaires and narratives in the focus groups. In the context investigated, the social workers revealed that the power of their work in health and the use of instrumentality is marked by dialogue and listening to the user, by the reception aimed at the humanization of care and the pursuit of fruition of access

\footnotetext{
1 Trabalho apresentado no Congresso Brasileiro Ciência e Sociedade (CBCS 2019), promovido pelo Centro Universitário Santo Agostinho, de 03 a 05 de outubro de 2019, em Teresina-PI.

2 Mestra em Políticas Públicas pela Universidade Federal do Piauí (UFPI). E-mail: flower_violeta@hotmail.com
} 


\section{CONGQEESSOCIENCIAESOCIEDADE \\ Inovação, Diversiliade e Sustentahilitiade}

mediated by dense processes of referrals to Rede de Atenção à Saúde and to Rede Socioassistencial, emphasize their daily work in the defense of life and citizenship.

Keywords: Secondary Care. Sistema Único de Saúde. Work. Social Service. Instrumentality

\section{INTRODUÇÃO}

A análise do estudo refere-se à discussão da instrumentalidade presente no trabalho do assistente social desenvolvido no cotidiano dos serviços de saúde de Média Complexidade no município de Timon-MA. A temática tem relevância à medida que tem enfoque no trabalho da assistente social nesse nível de atenção à saúde, pois a Média Complexidade tem sido apontada como um entrave para a efetivação da integralidade no SUS (PIMENTA, 2015; TEMPORÃO, 2007). O artigo apresenta um delineamento da pesquisa de mestrado do Programa de Pós-Graduação em Políticas Públicas na Universidade Federal do Piauí, intitulada "O trabalho do assistente social na saúde de Média Complexidade no município de Timon: avanços e desafios da e na profissão" e a partir desse estudo foi elaborado o presente artigo.

O cenário da pesquisa é o município de Timon, uma cidade de grande porte do estado do Maranhão, com a população de 155.460 habitantes (IBGE, 2010), quarta maior cidade do Estado do Maranhão, em número de habitantes. O município compõe a Região Integrada de Desenvolvimento da Grande Teresina (RIDE), conforme Decreto no. 4.367, de 09 de setembro de 2002, e é sede da Região de Saúde de Timon, também composta pelos municípios de Parnarama, Matões e São Francisco do Maranhão. No estudo é analisado o trabalho do assistente social desenvolvido nos serviços de saúde de Média Complexidade, esta compreendida como:

A média complexidade ambulatorial é composta por ações e serviços
que visam atender aos principais problemas e agravos de saúde da
população, cuja complexidade da assistência na prática clínica
demande a disponibilidade de profissionais especializados e a
utilização de recursos tecnológicos, para o apoio diagnóstico e
tratamento (BRASIL, 2007, p. 18).

Acrescenta-se que o assistente social é reconhecido pela intervenção na esfera da assistência, do planejamento, da gestão, no trabalho junto aos movimentos sociais, nos conselhos de direitos e como gestores de políticas públicas, enfim, trata-se de uma 


\section{congenESOO CIENCIAESOCIEDADE

profissão reconhecida pela Lei n. 8.662/93, que historicamente constrói o seu fazer na relação com o "real em movimento" (MARX, 2006), intervindo tanto na viabilização do acesso ao direito, no acesso à informação, quanto nas mediações de conflitos, sempre na direção de conceder respostas pertinentes às sequelas da questão social (IAMAMOTO, 2008) na garantia de direito dos usuários.

Para garantir o direito à saúde preconizado no art. 196, da Constituição Federal de 1988, que reconhece a saúde como direito de todos e dever do Estado, o assistente social em seu trabalho intervém por meio do uso da instrumentalidade. Ao se utilizar da instrumentalidade o assistente social dispõe de instrumentos e técnicas, que são um dos elementos constitutivos da dimensão técnico-operativa, sendo o modo de aparecer da profissão, onde é revelado a sua imagem (GUERRA, 2009).

O artigo remete a necessidade de aprofundar a discussão sobre a instrumentalidade, e o uso dos instrumentos e técnicas no cotidiano dos serviços de saúde de Média Complexidade em Timon, bem como as respostas profissionais do assistente social no atendimento às demandas advindas dos usuários nos serviços de saúde.

\section{METODOLOGIA}

A metodologia adotada foi a pesquisa qualitativa (MINAYO, 2001; GIL, 2007), com análise de literatura, pesquisa documental e pesquisa de campo. A pesquisa utilizou o método histórico-dialético e tem como fundamentação teórica alguns autores como lamamoto (2002, 2008), Guerra (2009, 2011), Joazeiro (2002, 2008, 2018), Santos e Noronha (2011), Fávero (2007), Sousa (2008), dentre outros.

Neste estudo, as participantes foram as cinco assistentes sociais que trabalham nas cinco instituições de saúde de Média Complexidade do município de Timon que contam com o trabalho da assistente social na equipe profissional. Assim, o cenário da pesquisa são as instituições: Unidade de Saúde Dr. Antônio Martins Albuquerque Pedreira (Policlínica), Centro de Atenção Integrada à Saúde da Mulher (CAISM), Centro Integrado de Atendimento Educacional Especializado Maria do Carmo Viana Neiva 


\section{CONQEEESSOCIENCIAESOCIEDADE \\ Inovação, Diversiliade e Sustentahilitiade}

(CIAEE), Hospital Municipal do Parque Alvorada (HPA) e Centro de Atenção Especializada e Materno Infantil (CAEMI).

Em relação à Ética na pesquisa, a realização desse estudo seguiu rigorosamente as orientações previstas nas Resoluções №. 466/2012 e №. 510/2016, do Conselho Nacional de Saúde. O projeto de pesquisa foi aprovado pelo Comitê de Ética em Pesquisa da Universidade Federal do Piauí (UFPI), no dia 18 de fevereiro de 2019, com CAE №. 05277219.8.0000.5214 e parecer №. 3.152.353, além de ter sido apreciado pela Comissão de Ética da Secretaria Municipal de Saúde de Timon (MA). Foi realizada a pesquisa de campo com as cinco assistentes sociais supracitadas mediante assinatura dos Termos de Consentimento Livre e Esclarecido (TCLE) pelas participantes.

A primeira etapa da pesquisa de campo consistiu na coleta de dados a partir do preenchimento de questionários pelas assistentes sociais que atuam nos referidos serviços, seguida da realização de dois grupos focais. As narrativas nos grupos focais se constituem em fonte empírica principal e as respostas aos questionários, em fonte de informação específica. A análise desse material permitiu identificar os pontos de vista e os sentidos das experiências compartilhadas, suas vivências do fazer profissional das participantes da pesquisa.

O material advindo dos questionários semiabertos e as transcrições das narrativas das assistentes sociais nos grupos focais foram analisados e categorizados em consonância com o objetivo do estudo, buscando esclarecer as interrogações, bem como aprofundar análise, no entrecruzamento e nas especificidades de cada uma das fontes, procurando preencher as lacunas das fontes utilizadas estabelecendo um "diálogo entre elas" buscando constituir uma relação de sentidos (JOAZEIRO, 2002).

$\mathrm{Na}$ análise inspiramo-nos em Joazeiro (2008) e Rosa (2005), ao privilegiar o uso da palavra, ou seja, a atividade de linguagem das assistentes sociais nos grupos focais e discussão em grupo, para dizer do seu trabalho na saúde na Média Complexidade, e nesse estudo enfatizando a instrumentalidade. As protagonistas da atividade de trabalho, por meio da palavra, "disseram da sua história singular, mas também da história coletiva dos demais trabalhadores da saúde" (JOAZEIRO, 2008, p. 19). 


\section{congęSSOC CIENCIAESOCIEDADE

Na redação do artigo optamos pela apresentação do material oriundo dos dois grupos focais e dos questionários a serem identificados a partir da seguinte orientação: identificamos a assistente social através da seguinte forma 1a Assistente Social (1a AS), 2a Assistente Social (2 aS), e assim, sucessivamente, seguida da natureza da fonte, se decorrente do grupo focal (GF) ou do questionário (Q). Nossa opção pelo uso desse critério baseado na ordem de aceite de participação da pesquisa deu-se com o objetivo de preservar a identidade das participantes da pesquisa.

\section{RESULTADOS E DISCUSSÃO}

O uso da linguagem no trabalho do Serviço Social, como relata a participante da pesquisa, ao narrar sobre sua abordagem e escuta do usuário "onde a gente faz aquela abordagem da necessidade de cada usuário. Então, eu abordo através de conversa, tento descobrir o que que traz ele lá na [declina o nome da instituição] e a maioria das vezes é como eu falei, é a questão do atendimento, os especialistas [...]" (Fragmento da narrativa da 5a AS-GF2), e no mesmo sentido de considerar o diálogo, a linguagem como matéria-prima do Serviço Social, pois segundo lamamoto (2002, p.101) "o Serviço Social, como uma das formas institucionalizadas de atuação nas relações entre os homens no cotidiano da vida social, tem como recurso básico de trabalho a linguagem".

Conforme Guerra (2009) a instrumentalidade é uma propriedade ou um determinado modo de ser que a profissão adquire dentro das relações sociais, no confronto entre as condições objetivas e subjetivas do exercício profissional. Portanto, é uma propriedade sócio-histórica da profissão que possibilita aos assistentes sociais definirem sua intencionalidade através de respostas profissionais.

A forma como o trabalho da assistente social é desenvolvida revela o uso da instrumentalidade, bem como dos instrumentos e técnicas, estando em consonância com as concepções das autoras supracitadas, pois expressam a intencionalidade do profissional e como desenvolvem seu trabalho, conforme expresso nas narrativas:

[...] a gente tem as atividades diárias [...] visitas domiciliares, atendimento individual ou grupal, a gente tem recadastramento 
que a gente faz anualmente. [...] todo ano eu fico fazendo o recadastramento dessas mães, aí, crianças e adolescentes, organização dos prontuários, orientação sobre benefícios assistenciais, declaração de atendimentos, declarações mensais para recebimento de ajuda de custo para o pessoal da zona rural.[...] Aí tem encaminhamento para tratamento fora de domicílio que é o velho TFD que a gente já conhece, é [...] orientação e entrega de formulários para passe livre que é o interestadual. 0 [formulário] municipal eu sempre deixo a cargo do CRAS, não é? E as visitas institucionais que a gente também faz, a gente visita as instituições, no caso a gente visita o Ministério Público, Defensoria, qualquer mudança de processo que precise de algum pai e mãe [...] negligência que eles chamam... E tem o acompanhamento social que eu faço, estudo social, e o acompanhamento familiar e mesmo você fazendo, assim.

Fragmento da narrativa da 2ªS- GF1 (destaques nossos).

[...] estudo social, não é um acompanhamento social, você faz o estudo social, dá o parecer, mas o acompanhamento familiar eu vou fazer visitas, chamo para conversar, anterior a nossa reunião eu estava fazendo um acompanhamento porque agora eu vi uma quantidade de desrespeito à instituição, faltando, quer voltar na hora que quer, e eu tô pedindo o comparecimento das mães, a lista de espera, isso aí não existia, mas agora eu comecei a colocar porque tão reclamando demais que a fila não anda.

Fragmento da narrativa da 2a AS- GF1 (destaques nossos).

Observa-se esse esforço da participante do grupo de realizar um processo de aprofundamento gradual de sua análise à medida que a mesma passa da etapa de quem elabora uma lista descritiva de procedimentos, para uma organização temporal separando atividades diárias, semanais, anuais e as eventuais. Retomamos a categoria temporalidade, quando a segunda assistente social relaciona suas atividades nessa organização temporal, e alude a "temporalidade burocrática, aquela que predefine a relação do saber com o contínuo do tempo" (JOAZEIRO, 2018, p. 42). Na sua narrativa se apreende que o fio condutor que marca o processo de sua análise vai na direção de buscar a atividade mais específica de realização continuada, para aquelas de maior complexidade.

[...] Aí tem encaminhamento para tratamento fora de domicílio que é o velho TFD que a gente já conhece, é [...] orientação e entrega de formulários para passe livre que é o interestadual. O [formulário] municipal eu sempre deixo a cargo do CRAS, não é?

Fragmento da narrativa da 2a AS- GF1 (destaques nossos). 
No percurso de sua narrativa a participante do grupo revela sua intimidade com o trabalho realizado e com os sentidos dessa atividade para o usuário do serviço de saúde, mas também se preocupa com o motivo de estar presente naquela atividade de grupo focal, e por isso brinda a todos os presentes com uma rica narrativa que ao mesmo tempo que descreve o seu fazer explicita sua reflexão sobre os sentidos dessa ação. Apreende-se de sua narrativa o processo de reflexão que se instaura na constância de sua participação, à medida que descreve as atividades que realiza num cotidiano marcado por múltiplas convocações, a assistente social, delineia num curtíssimo espaço de tempo uma densa reflexão sobre os itinerários de seus saberes. Processo explicitado, por exemplo, ao situar no tempo e na história recente desde os primórdios da implantação do SUS o direito a requerer o Tratamento Fora de Domicílio (TFD). Ao utilizar a expressão "o velho TFD" alude ao tempo que decorre da instauração desse direito ${ }^{3}$, e da diminuição gradual de seu alcance para a população que precisa deixar sua cidade em busca de acesso a cuidado de saúde mais complexos.

$\mathrm{Na}$ indagação sobre "O [formulário] municipal eu sempre deixo a cargo do CRAS, não é?", ela revela através da pergunta final que está se referindo a uma norma cara à profissão de respeitar a "rede de petição e de compromisso" que se instaura no território, de forma a preservar as ações que competem à rede de atenção socioassistencial da Política de Assistência Social para que sejam realizadas por estas, evitando retrabalhos e sobreposição de ações entre as políticas sociais públicas. A rede de petição e compromisso se articula a "rede de relações existentes inter e intra equipamento assistencial analisado, e nesta rede, esclarecer os pedidos e compromissos assumidos entre os diversos atores implicados na arena operacional e decisória" (FRANCO; MEHRY, 2007, p. 1) se constitui num aspecto fundamental.

Ainda valorizando a potência da narrativa da participante do Grupo Focal, retomamos o fragmento onde a mesma atinge o maior nível de complexidade presente no seu trabalho, quando para além das situações de agravos à saúde, de

\footnotetext{
${ }^{3}$ Portaria № 55, de 24 de fevereiro de 1999, dispõe sobre a rotina do Tratamento Fora de Domicilio no Sistema Único de Saúde - SUS, com inclusão dos procedimentos específicos na tabela de procedimentos do Sistema de Informações Ambulatoriais do SIA/SUS e dá outras providências.
} 


\section{CONQEFESSOCIENCIAESOCIEDADE

busca de acesso a consultas e a exames especializados, elas são demandadas a produzir uma consistente interface entre a realização de "visitas institucionais que a gente também faz, [...], no caso a gente visita o Ministério Público, Defensoria, qualquer mudança de processo que precise de algum pai e mãe [por] negligência que eles chamam. E tem o acompanhamento social que eu faço estudo social, e o acompanhamento familiar" (destaques nossos).

Trata-se da interface entre violação de direitos e a defesa dos direitos individuais ou sociais que é parte inequívoca do trabalho do assistente social. Ao declinar que nas situações de suspeita ou de confirmação de negligência a necessidade de saber diferenciar o uso dos instrumentos da profissão, dentre eles enumera o acompanhamento social, do estudo social e o parecer (destaques nossos).

Santos e Noronha (2011, p. 51) assinalam que os instrumentos privilegiados na bibliografia técnica do Serviço Social tem sido: o parecer, que se explica em função do grande número de assistentes sociais que trabalham no Poder Judiciário e na Vara da Infância e Juventude, a entrevista, a reunião de grupo e a visita domiciliar (op. cit., p. 51).

O processo de escolha dos instrumentos não é neutro, ele é feito levando em consideração as condições objetivas do trabalho, as finalidades da ação, da profissão e da instituição, "bem como pensar sobre a demanda, sua funcionalidade frente a realidade em que a população está inserida, as habilidades necessárias ao seu manuseio e seu compromisso ético político" (SANTOS; NORONHA, 2011, p. 50). É esse percurso que transita entre o sentido empírico da escolhe e do uso dos instrumentos e o sentido epistemológico e técnico-operativo que a participante do grupo explicita em sua narrativa.

Acrescentam-se às respostas aos questionários das assistentes sociais referentes ao uso de instrumentais, pois se indagava: Quais são os instrumentos e técnicas de intervenção utilizados em seu trabalho como assistente social?

Entrevistas, acolhimento (escuta ativa), visitas domiciliares e institucionais, trabalho em grupo, reuniões, estudo social, parecer social. Acompanhamento social ( 2 a AS-Q). 


\section{CONGEFSSO CIENCIAESOCIEDADE}

Acompanhamento social a pacientes internos, relatórios, registros, fichas, encaminhamentos, declaração social e visitas aos leitos de pacientes. Escuta individualizada, evolução diária, censo, aconselhamento social, individual e grupal (4a AS-Q- destaques nossos).

$\mathrm{Na}$ realidade o trabalho da assistente social em uma instituição requer o uso da entrevista, porém diante das dificuldades em padronizar rotinas e procedimentos de intervenção, devido as dificuldades de instrumentais, das condições de trabalho, o profissional precisa usar a criatividade, trabalhando de forma limitada, atuando apenas com os poucos instrumentos que a instituição dispõe (5a AS-Q).

Dentre os instrumentos e técnicas que as assistentes sociais relataram utilizar em seu trabalho destacamos: estudo social, relatório e parecer social, visitas domiciliares e institucional, e reunião. O estudo social "é um processo metodológico específico do Serviço Social, que tem por finalidade conhecer com profundidade, e de forma crítica, uma determinada situação ou expressão da questão social, especialmente nos seus aspectos socioeconômicos e culturais" (FÁVERO, 2007, p. 25).

O relatório social é definido pela mesma autora como "uma apresentação descritiva e interpretativa de uma situação expressa na questão social”, e já o parecer social é "a opinião fundamentada que o assistente social emite sobre a situação estudada; envolve também esclarecimentos e análises, com base em conhecimento específico do Serviço Social" (FÁVERO, 2007, p. 28-30).

Com relação a visita domiciliar tem por objetivo "conhecer as condições e modos de vida da população usuária em sua realidade cotidiana, ou seja, no local onde ela estabelece suas relações do dia a dia: em seu domicílio" (SOUSA, 2008, p. 128). Por sua vez, a entrevista é "um diálogo, um processo de comunicação direta entre o assistente Social e um usuário (entrevista individual), ou mais de um (entrevista grupal)" (op. cit., p. 126).

Outro instrumento de trabalho é a visita institucional e Sousa (2008) aponta três motivos pelos quais o assistente social realiza essa visita, como visitar uma instituição com a qual o usuário mantém vínculo; conhecer um trabalho desenvolvido por uma instituição; ou realizar uma avaliação da cobertura e da qualidade dos 


\section{congęSSOC CIENCIAESOCIEDADE

serviços prestados por uma instituição (op. cit., p. 129). O mesmo autor considera a reunião como um instrumento de trabalho que o assistente social utiliza com 0 objetivo de estabelecer uma espécie de reflexão sobre determinado tema e envolve uma tomada de decisão (op. cit., p. 127).

Destacam-se também como técnicas de trabalho o atendimento e acompanhamento social, conforme relata uma das profissionais que:

[...] no [declina o nome de uma instituição] não tem atendimento social, não tem acompanhamento. É um atendimento, e muitas vezes essa usuária, eu não a vejo novamente, porque ela passa ali para fazer um exame. É uma consulta, ela só vai voltar daqui a seis meses para consulta e no [declina o nome de outra instituição] é acompanhamento, eu chego a dar alta dela e fico acompanhando por mais tempo.

Fragmento da narrativa da 1a AS- GF1.

Segundo lamamoto (2008) o assistente social não utiliza apenas esse arsenal de técnicas como um mero instrumento operativo, mas de forma a abranger o conhecimento como um meio de trabalho, indispensável ao trabalhador especializado no seu cotidiano profissional. Guerra (2009) afirma que o assistente social utiliza tais instrumentos, enquanto profissional inserido na divisão social e técnica do trabalho, fundamentados em bases teórico-metodológica, ético-política e técnico-operativa, inerentes à sua prática profissional. Assim, observa-se que as narrativas das assistentes sociais se coadunam com as concepções das autoras e no seu trabalho nos serviços de saúde de Média Complexidade é significativo o uso da instrumentalidade.

\section{CONSIDERAÇÕES FINAIS}

Diante do exposto, identificou-se que as assistentes sociais que trabalham nas instituições de saúde de Média Complexidade de Timon têm buscado exercer suas atribuições privativas e competências profissionais em conformidade com as legislações e as normativas legais, pautadas no uso da instrumentalidade e nas dimensões teórico-metodológica, ético-política e técnico-operativa da profissão.

O olhar atento ao trabalho das assistentes sociais no campo da saúde de Média Complexidade, revela que há demanda aos profissionais de respostas às expressões da 


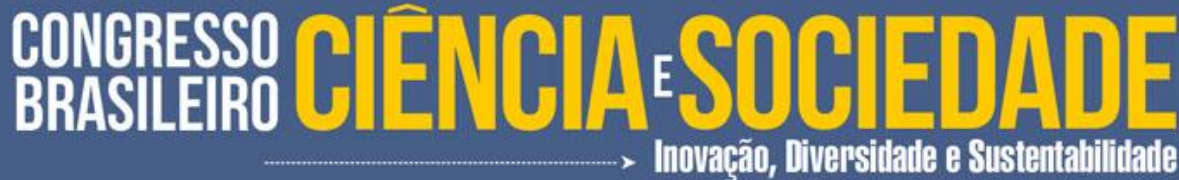

questão social, fato que indica que no território transita a busca pela tessitura da articulação inter e intra serviços por meio da rede de petição e compromisso, e que a assistente social e os demais profissionais da equipe multiprofissional nela atuam juntamente com os demais serviços da rede de atendimento.

No contexto investigado, as assistentes sociais, em sua maioria, demonstraram que a potência do seu trabalho na saúde está marcada pelo diálogo e pela escuta do usuário, pelo acolhimento visando a humanização do atendimento e a busca da fruição do acesso mediadas por densos processos de encaminhamentos à Rede de Atenção à Saúde e para a Rede Socioassistencial, considerando que o Serviço Social utiliza a linguagem como "recurso básico de trabalho" (IAMAMOTO, 2002), e assinalaram, com ênfase no seu trabalho diário, a presença marcante de ações centradas na defesa da vida e da cidadania.

\section{REFERÊNCIAS}

BRASIL. Conselho Nacional de Secretários de Saúde. Brasil: Coleção Progestores - Para entender a gestão do SUS, 1. Sistema Único de Saúde / Conselho Nacional de Secretários de Saúde. Brasília, DF: CONASS, 2007.

FÁVERO, Eunice Teresinha. O estudo social. Fundamentos e particularidades de sua construção na área judiciária. In: CFESS (org). 0 estudo social em perícias, laudos e pareceres técnicos: contribuição ao debate no judiciário, no penitenciário e na previdência social. São Paulo, Cortez, 2007.

FRANCO, T. B.; MERHY, E. E. O uso de ferramentas analisadoras para apoio ao planejamento dos serviços de saúde: o caso do Serviço Social do Hospital das Clínicas da Unicamp (Campinas, SP). In: MERHY, E. E. et al. $\mathbf{O}$ trabalho em saúde: olhando e experenciando o SUS no cotidiano. São Paulo: Hucitec. 2007.

GIL, A. C. Métodos e Técnicas de Pesquisa Social. 5. ed. 8. reimp. São Paulo: Atlas, 2007.

GUERRA, Y. G. A instrumentalidade do Serviço Social.SP, Cortez, 2011.

GUERRA, Y. G. A dimensão investigativa do Serviço Social. In: Conselho Federal de Serviço Social. Associação Brasileira de Ensino e Pesquisa em Serviço Social. Direitos Sociais e Competências Profissionais. 2009. v.1. p. 701-718. 


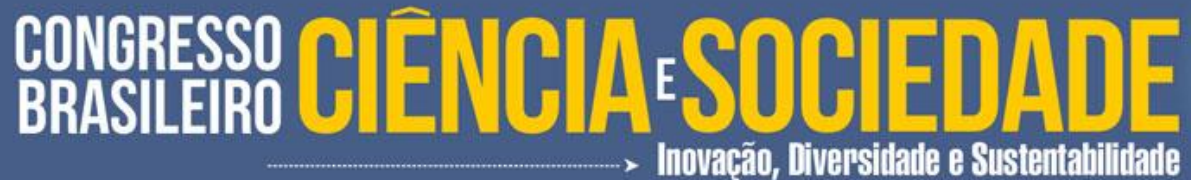

IAMAMOTO, M. V. Renovação e conservadorismo no Serviço Social: ensaios críticos. SP, Cortez, 2002.

IAMAMOTO, M. V. Serviço Social na contemporaneidade: trabalho e formação profissional. São Paulo: Cortez, 2008.

IBGE. Instituto Brasileiro de Geografia e Estatística. Censo de 2010. Município de Timon. Disponível em: https://cidades.ibge.gov.br/v4/brasil/ma/timon/panorama. Acesso em: 15 de setembro de 2017.

JOAZEIRO, E. M. G. Estágio Supervisionado: experiência e conhecimento. Santo André: ESETec, 2002.

JOAZEIRO, E. M. G. Supervisão de Estágio: formação, saberes, temporalidades. Santo André: ESETec, 2008.

JOAZEIRO, E. M. G. Supervisão Acadêmica e de Campo: relação entre saberes.Teresina:Edufpi, 2018.

MARX, K. O capital: crítica da economia política. Rio de Janeiro: Civilização Brasileira, 2006.

MINAYO, Maria Cecília de Souza (org.). Pesquisa Social: Teoria, método e criatividade. 18 ed. Petrópolis: Vozes, 2001.

PIMENTA, A. L. Presidente do COSEMS afirma que prefeituras investem mais que Estados e União no financiamento do SUS. Jornal do Cremesp. Edição 215, 7/2005. Disponível em: http://www.cremesp.com.br/?siteAcao=Jornal\&id=531. Acesso em: 10 de agosto de 2016.

ROSA, M. I. Usos de si no trabalho e Densificação: nova modalidade. In: FÍGARO, R. (Org.) Gestão da comunicação: no Mundo do Trabalho, Educação, Terceiro Setor e Cooperativismo. São Paulo: Atlas, 2005, p. 117-34.

SANTOS, C. M. dos; NORONHA, K. O estado da arte sobre os instrumentos e técnicas na intervenção profissional do assistente social - Uma perspectiva crítica. In FORTI, V. GUERRA, Y. Serviço Social: temas, textos e contextos. Rio de Janeiro: Lumen Juris, 2011, p. 47-63.

SOUSA, C. T. A prática do assistente social: conhecimento, instrumentalidade e intervenção profissional. Emancipação. Vol. 8. Ponta Grossa, 2008. P. 119-132.

TEMPORÃO, J. G. (entrevista) Revista Conasems, ano II, n.23, p.5-12, mai./jun. 2007. Disponível em http://www.conasems.org.br/files/revista23.pdf. Acesso em: 15 de março de 2016. 